\title{
Cloning, Soluble Expression and Purification of High Yield Recombinant hGMCSF in Escherichia coli
}

\author{
Krishna M.P. Das ${ }^{1}$, Sampali Banerjee ${ }^{1}$, Nivedita Shekhar ${ }^{2}$, Karpagavalli Damodaran ${ }^{3}$, \\ Rahul Nair ${ }^{4}$, Sandeep Somani ${ }^{5}$, Veena P. Raiker ${ }^{3}$, Shweta Jain ${ }^{3}$ and Sriram Padmanabhan ${ }^{6, *}$
}

1 Clone Development Team, Lupin Limited, Biotechnology R \& D, Gat \#1156, Ghotawade Village, Mulshi Taluka, Pune-411042, India; E-Mails: krishnap@lupinpharma.com (K.M.P.D.); sampalibanerjee@ lupinpharma.com (S.B.)

2 Mammalian Bioassay Team, Lupin Limited, Biotechnology R \& D, Gat \#1156, Ghotawade Village, Mulshi Taluka, Pune-411042, India; E-Mail: niveditashekhar@lupinpharma.com

3 Analytical development Team, Lupin Limited, Biotechnology R \& D, Gat \#1156, Ghotawade Village, Mulshi Taluka, Pune-411042, India; E-Mails: karpagavallid@lupinpharma.com (K.D.); veenaraiker@lupinpharma.com (V.P.R.); shwetajain@lupinpharma.com (S.J.) Upstream Development Team, Lupin Limited, Biotechnology R \& D, Gat \#1156, Ghotawade Village, Mulshi Taluka, Pune-411042, India; E-Mail: rahulnair@lupinpharma.com

5 Downstream Development Team, Lupin Limited, Biotechnology R \& D, Gat \#1156, Ghotawade Village, Mulshi Taluka, Pune-411042, India; E-Mail: sandeepsomani@lupinpharma.com

6 Biotechnology R\&D, Lupin Limited, Biotechnology R \& D, Gat \#1156, Ghotawade Village, Mulshi Taluka, Pune-411042, India

* Author to whom correspondence should be addressed;

E-Mail: srirampadmanabhan@lupinpharma.com; Tel.: +91-20-66549800; Fax: +91-20-66549807.

Received: 21 January 2011; in revised form: 17 February 2011 / Accepted: 20 March 2011 / Published: 22 March 2011

Abstract: Expression of human granulocyte macrophage colony stimulating factor (hGMCSF), a cytokine of therapeutic importance, as a thioredoxin (TRX) fusion has been investigated in Escherichia coli BL21 (DE3) codon plus cells. The expression of this protein was low when cloned under the T7 promoter without any fusion tags. High yield of GMCSF was achieved ( $88 \mathrm{mg} / \mathrm{L}$ of fermentation broth) in the shake flask when the gene was fused to the $E$. coli TRX gene. The protein was purified using a single step $\mathrm{Ni}^{2+}$-NTA affinity chromatography and the column bound fusion tag was removed by on-column cleavage with enterokinase. The recombinant hGMCSF was expressed as a soluble and 
biologically active protein in $E$. coli, and upon purification, the final yield was $\sim 44 \mathrm{mg} / \mathrm{L}$ in shake flask with a specific activity of $2.3 \times 10^{8} \mathrm{U} / \mathrm{mg}$. The results of Western blot and RP-HPLC analyses, along with biological activity using the TF-1 cell line, established the identity of the purified hGMCSF. In this paper, we report the highest yield of hGMCSF expressed in E. coli. The bioreactor study shows that the yield of hGMCSF could be easily scalable with a yield of $\sim 400 \mathrm{mg} / \mathrm{L}$, opening up new opportunities for large scale production hGMCSF in E. coli.

Keywords: human granulocyte macrophage colony stimulating factor; on-column cleavage; TRX fusion; IMAC; enterokinase

\section{Introduction}

Human granulocyte macrophage colony stimulating factor (hGMCSF) is a cytokine, secreted by macrophages, $\mathrm{T}$ cells, mast cells, endothelial cells and fibroblasts in response to immune and inflammatory stimuli. Mature human GMCSF is a glycoprotein and consists of 127 amino acid residues, with four cysteines being involved in two disulfide bonds [1]. Human GMCSF is an important therapeutic cytokine used in the treatment of myeloid leukemia, neutropenia and aplastic anemia [2]. Many attempts have been undertaken to synthesize biologically active recombinant hGMCSF; however, transfected mammalian cells are not preferred as an expression system for producing GMCSF for biological and structural studies due to low expression levels and the presence of contaminating CSFs secreted by the mammalian cells themselves [3]. This problem can be handled using an Escherichia coli expression system to produce large quantities of recombinant protein. E. coli has widely been used for recombinant protein production [4] due to its ability to grow rapidly and at high density on inexpensive substrates, combined with its well-characterized genetics. A variety of cloning and expression vectors, recombinant fusion tags and mutant strains are available for commercial manufacture of recombinant proteins [5,6]. Although attractive, some potential disadvantages of this expression system include lack of post translational modifications [7], lack of the proper secretion system for efficient release of produced protein into the growth medium, inefficient cleavage of amino terminus methionine resulting in lower protein stability and increased immunogenicity together with the limited ability to facilitate extensive disulfide bond formation and improper folding resulting in inclusion body formation [8].

Protein misfolding or inaccurate processing by cellular molecular chaperones ultimately results in formation of biologically inactive protein. Hence, optimization of the expression conditions or laborious refolding studies is required to achieve an active protein. Also, many eukaryotic proteins cannot be expressed successfully in E. coli, and the conventional method to express such proteins is as fusion tags [9,10]. There have been reports of expression of hGMCSF as intein fusion entities [11] and GCSF fusion proteins [12], with all of them being expressed as insoluble protein aggregates. Soluble protein production in E. coli is still a major bottleneck for investigators, and a couple of efforts have been reported to improve the solubility or folding of recombinant protein produced in E. coli [13]. These include strategies like co-expression of chaperone proteins such as GroES, GroEL, DnaK and 
DnaJ, lowering incubation temperature, use of weak promoters, addition of sucrose and betaine in the growth media, use of richer media with phosphate buffer such as terrific broth (TB), use of signal sequence to export the protein to the periplasmic fraction and use of fusion tags to aid in expression and protein purification [9]. A number of fusion tags are available for the ease of expression and purification of recombinant proteins $[14,15]$ and mostly they promote purification of the fused protein, though some of them (thioredoxin, NusA, etc.) are also reported to increase the solubility of the target proteins in comparison to unfused proteins when overexpressed in E. coli [16]. In this paper, we describe the overexpression of hGMCSF as a soluble thioredoxin (TRX)-fusion and purification to homogeneity with very high yield after removal of the fusion tag by enterokinase digestion.

\section{Results and Discussion}

\subsection{Cloning and Expression of $h G M C S F$}

hGMCSF was cloned in pET21a and expressed in BL21 (DE3) codon plus cells in the shake flask scale (100 mL LB). As seen in Figure 1a, there was no visible expression of recombinant hGMCSF by SDS-PAGE (upper panel, lane 2) and the expression was evident only after immunoblot analysis (lower panel, lane 2). As the poor expression of GMCSF was unsuitable for any further experimentation, the gene was cloned as a TRX fusion and the expression was carried out in the same cell line as described before. The results shown in Figure $1 \mathrm{~b}$ indicate that the expression of TRX-GMCSF in soluble form (Figure 1b, lane 2). Bioreactor study on a $2 \mathrm{~L}$ scale (Figure 2) was carried out using in-house medium and the total protein in the soluble fraction was found to be $4.95 \mathrm{~g} / \mathrm{L}$, which corresponds to nearly a yield of $400 \mathrm{mg}$ of crude GMCSF protein/L of fermentation medium.

\subsection{Purification of TRX-hGMCSF Followed by Separation of hGMCSF from the Fusion Tag}

The TRX-GMCSF, containing a six His-tag in between the fusion partners TRX and GMCSF, was purified through $\mathrm{Ni}^{2+}$-NTA sepharose following the protocol described in the Experimental section. The purified fusion protein (Figure 3a, lane 2) after enterokinase cleavage and second round of purification yielded $>95 \%$ pure hGMCSF protein (Figure 3a, lane 3) with a final yield of $\sim 44 \mathrm{mg} / \mathrm{L}$ and a fold purification of 2.5 (Table 1). Immunoblot analysis with mouse monoclonal anti-hGMCSF antibody confirmed the identity of the purified protein, which has a theoretical molecular mass $14.4 \mathrm{kDa}$ (Figure 3b). The purity of the purified soluble GMCSF from the above fusion tag clone following the described method was analyzed by RP-HPLC and SE-HPLC for identity and similarity study with commercial GMCSF (Sigma, U.S.). RP-HPLC profiles of both soluble hGMCSF and commercial hGMCSF showed a similar pattern (Figure 4) at a retention time of 19.797 min with a purity of $\sim 95 \%$, which is better than the commercial protein ( $90.2 \%)$, indicating the efficient separation and purification of the protein of interest. The commercial hGMCSF used was procured from Sigma (G 5035) and the product is supplied as a lyophilized powder from a $10 \mathrm{mM}$ sodium citrate solution, $\mathrm{pH} 3.5$, with no other proteinous material. This was also evident from the profile, with the absence of any major peak other than hGMCSF peak. The SE-HPLC analysis was carried out to determine the presence of GMCSF related impurities like aggregation and different conformational forms [17]. The chromatogram (Figure 5) shows that the in-house purified hGMCSF is 
$\sim 92 \%$ pure with no detectable aggregation or other conformational forms, while purity of the commercial GMCSF preparation was found to be relatively less ( 86.8\%). The biological activity assay data indicate that the in-house hGMCSF is more active (potency 1.396) than the commercial preparation (Figure 6) and this could be partially attributed to the better purity of the in-house protein preparation.

For structural functional and clinical studies, therapeutic proteins in soluble active forms are in large demand. Human GMCSF protein has been described to function in the treatment of myeloid leukemia, neutropenia and aplastic anemia. Although, different expression systems have been explored to express recombinant human GMCSF (such as $\mathrm{CHO}$, yeast, bacteria, etc.), all of them have certain degrees of limitations. It has been reported that deglycosylated hGMCSF is at least 20-fold more active than its glycosylated variant expressed in CHO cells [18-20]. Similarly, Saccharomyces cerevisae derived GMCSF is clinically unsuitable due to varying degrees of glycosylation [21]. On the other hand, hGMCSF expressed in E. coli has been found to have similar biological activity to the native protein [22], indicating the non-essentiality of glycosylation for bioactivity of the GMCSF protein.

E. coli expression system offers several advantages like high expression level, rapid growth, simple media requirement, etc. Recombinant human GM-CSF produced in E. coli ends up in inclusion bodies (IBs) and has certain drawbacks, including complex processing, low specific activity, and poor in vitro renaturation [23]. Recently, hGMCSF has been reported to be expressed in E. coli BL21 (DE3) cells without IPTG induction as insoluble aggregates [1]. The protein has been purified after solubilization and the final yield was found to be $\sim 44 \mathrm{mg} / \mathrm{L}$. Also, intein fusion of hGMCSF has been reported in the recent past in E. coli [11] as well as in Pichia [24]. However, hGMCSF expression as a soluble protein in E. coli is host dependent, and in both the cases, authors have used dithiothreitol (DTT) to remove the fusion tag. Since DTT concentrations above $30 \mathrm{mM}$ are known to destabilize the disulfide bonds [25] and use of DTT to remove the fusion tag could hamper the two disulfide bonds that are crucial for hGMCSF activity [1], use of DTT in purification of GMCSF using such a strategy appears tricky and challenging.

High GC content and the presence of rare codons in the native human GMCSF gene are reported to be causative hurdles in the expression of recombinant human GMCSF (rhGMCSF) in E. coli [26]. In order to achieve better expression in E. coli, we have reduced the GC content of the hGMCSF gene at the 5' terminus and also used BL21 (DE3) codon plus cells for expression studies to supply rare codons required for efficient and optimal expression of the protein.

Here, we report the soluble expression of hGMCSF in E. coli and on-column cleavage and removal of the TRX fusion tag from hGMCSF for the first time. By following the process described in this article, we achieved $\sim 95 \%$ pure rhGMCSF protein with a specific activity of $2.3 \times 10^{8} \mathrm{U} / \mathrm{mg}$ with a potency of 1.396 as evident from the statistical analysis using the Parallel Line Assay (PLA) software. The yield of hGMCSF to $\sim 44 \mathrm{mg} / \mathrm{L}$ with a recovery of $\sim 46 \%$ observed in the present study is the highest to date [11]. Although fusion tags like intein $(55 \mathrm{kDa})$ have been reported for GMCSF fusions [11], the use of TRX as a fusion tag as described in this paper has an additional advantage. It offers higher molar yield of the protein of interest after tag removal since the size of the TRX tag is relatively smaller $(20 \mathrm{kDa})$. Our methodology of obtaining soluble GMCSF using the procedure as mentioned avoids the cumbersome procedures of refolding and purification of GMCSF from bacterial 
inclusion bodies, making the proposition attractive and user-friendly. Moreover, the expression of hGMCSF from the present construct in a bioreactor at $2 \mathrm{~L}$ scale yielded $\sim 400 \mathrm{mg} / \mathrm{L}$; thus presenting a promising cost-effective alternative for obtaining GMCSF protein in manufacturing scale.

Table 1. Summary of purification of hGMCSF expressed as TRX fusion from $100 \mathrm{~mL}$ flask culture.

\begin{tabular}{cccccccc}
\hline Fraction & $\begin{array}{c}\text { Volume } \\
(\mathbf{m L})\end{array}$ & $\begin{array}{c}\text { Protein } \\
(\mathbf{m g} / \mathbf{m L})\end{array}$ & $\begin{array}{c}\text { Total Protein } \\
(\mathbf{m g})\end{array}$ & $\begin{array}{c}\text { Total Activity } \\
(\mathbf{U})\end{array}$ & $\begin{array}{c}\text { Specific Activity } \\
(\mathbf{U} / \mathbf{m g})\end{array}$ & Fold Purification & \%Yield \\
\hline $\begin{array}{c}\text { Crude cell lysate } \\
\text { Purified TRX- }\end{array}$ & 10 & 2.39 & 23.9 & $2.19 \times 10^{8}$ & $9.16 \times 10^{6}$ & 1.0 & 100 \\
GMCSF fusion & 20 & 0.43 & 8.6 & $11.24 \times 10^{7}$ & $1.3 \times 10^{7}$ & 1.42 & 51 \\
Purified GMCSF & 20 & 0.22 & 4.4 & $10.20 \times 10^{7}$ & $2.3 \times 10^{7}$ & 2.5 & 46 \\
\hline
\end{tabular}

Figure 1. Expression analysis of pET21a-hGMCSF and pET32a-hGMCSF. (a) Upper Panel: SDS-PAGE analysis of pET21a-hGMCSF expression in BL21 DE3 codon plus cells with IPTG induction, showing absence of visible expression. Lane M: molecular weight Marker; lane 1: Empty vector control; lane 2: expression from pET21-hGMCSF. Lower Panel: Immunoblot using mouse monoclonal anti-hGMCSF antibody showing low expression level of hGMCSF; (b) SDS-PAGE analysis of TRX-hGMCSF fusion protein expression. The pET32a-hGMCSF construct was transformed into BL21 (DE3) codon plus cells. The cells were induced with $1 \mathrm{mM}$ IPTG for $3 \mathrm{~h}$. Lane M: Molecular weight Marker; lane 1: Crude cell lysate; lane 2: Soluble fraction and lane 3: Insoluble fraction. Arrows indicate TRX-GMCSF protein.

(a)

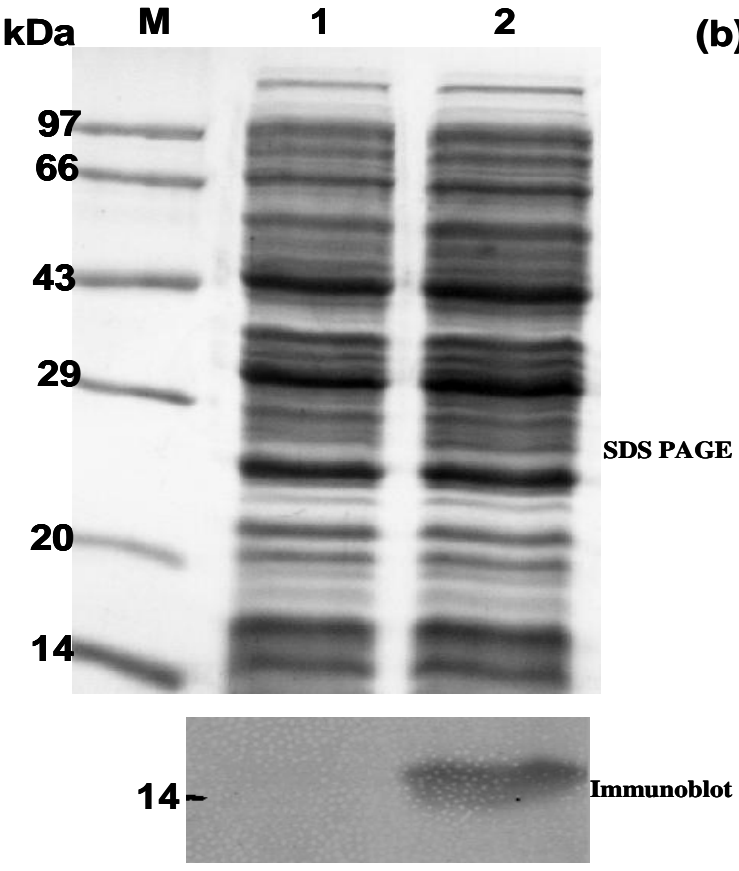

(b)

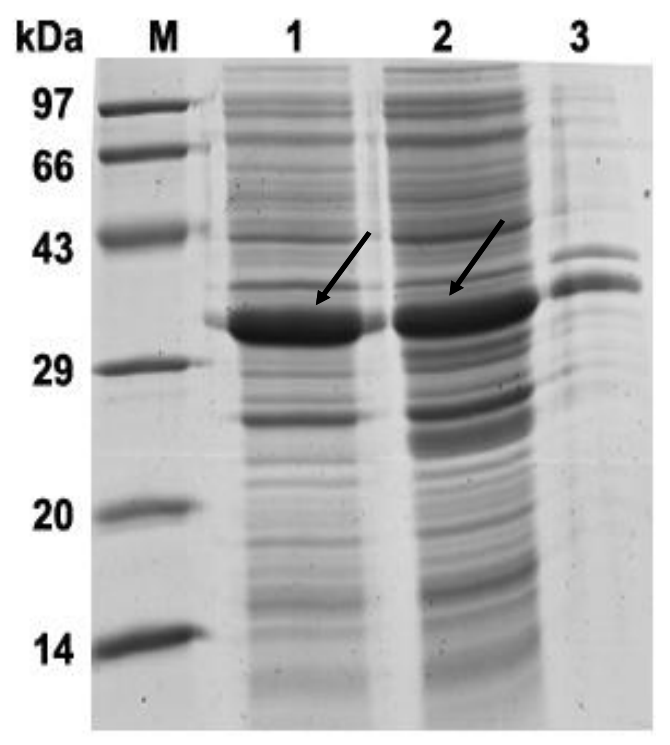


Figure 2. Expression of TRX-hGMCSF in $2 \mathrm{~L}$ fermenter in In-house medium. Various fermentation parameters were plotted against the batch hour. The cells were induced with $1 \mathrm{mM}$ IPTG at an $\mathrm{OD}_{600}$ of 18 and the culture was grown for another $3 \mathrm{~h}$ until it reached an $\mathrm{OD}_{600}$ of 37.

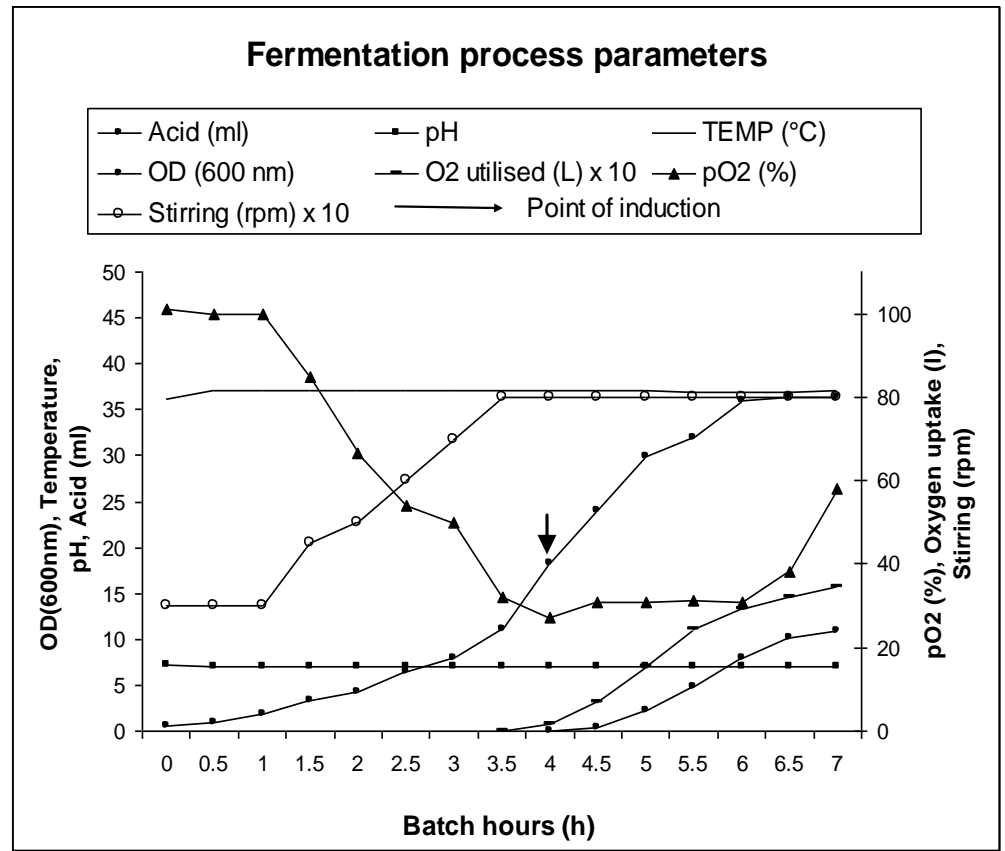

Figure 3. SDS-PAGE and Western blot analysis of purified hGMCSF. Soluble fraction containing TRX-hGMCSF was passed through Ni-NTA column and the fractions containing pure TRX-GMCSF were dialyzed and bound to Ni-NTA a second time in batch mode. The fusion protein was cleaved in the bound state with enterokinase enzyme in the presence of $1 \mathrm{mM} \mathrm{CaCl}$. The flow through containing hGMCSF was collected and analyzed. (a) SDS-PAGE showing different purification steps. Lane M: Molecular weight Marker; lane 1: Soluble fraction containing TRX-hGMCSF fusion; lane 2: Purified TRX-GMCSF fusion, lane 3: purified hGMCSF; (b) Immunoblot using mouse monoclonal anti-hGMCSF antibody to confirm the identity of hGMCSF. Lane 1: Soluble fraction containing TRX-hGMCSF fusion; lane 2: Purified TRX-GMCSF fusion; lane 3: purified hGMCSF. Arrows represent the purified hGMCSF in both SDS-PAGE and immunoblot.

(a)

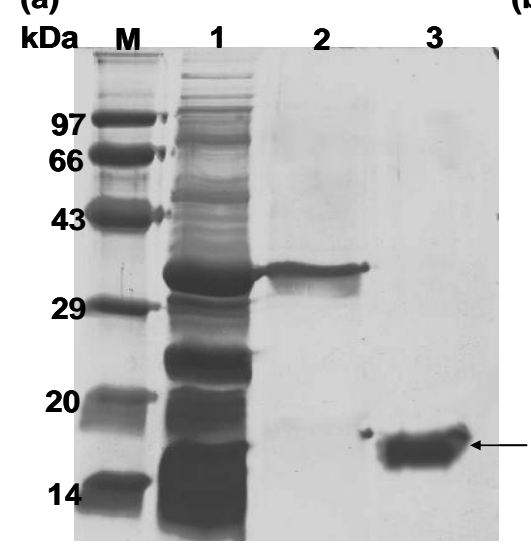

(b) 123 
Figure 4. Reverse phase chromatograph showing comparison of standard GMCSF and in-house purified hGMCSF with optimum mobile phase consisting of $0.1 \%$ TFA in $10 \%$ acetonitrile (a) and $0.1 \%$ TFA in $90 \%$ acetonitrile (b). Flow rate was maintained at $1 \mathrm{~mL} / \mathrm{min}$ and detection was at $215 \mathrm{~nm}$. Black line represents standard hGMCSF while red line indicates the in-house purified rhGMCSF.

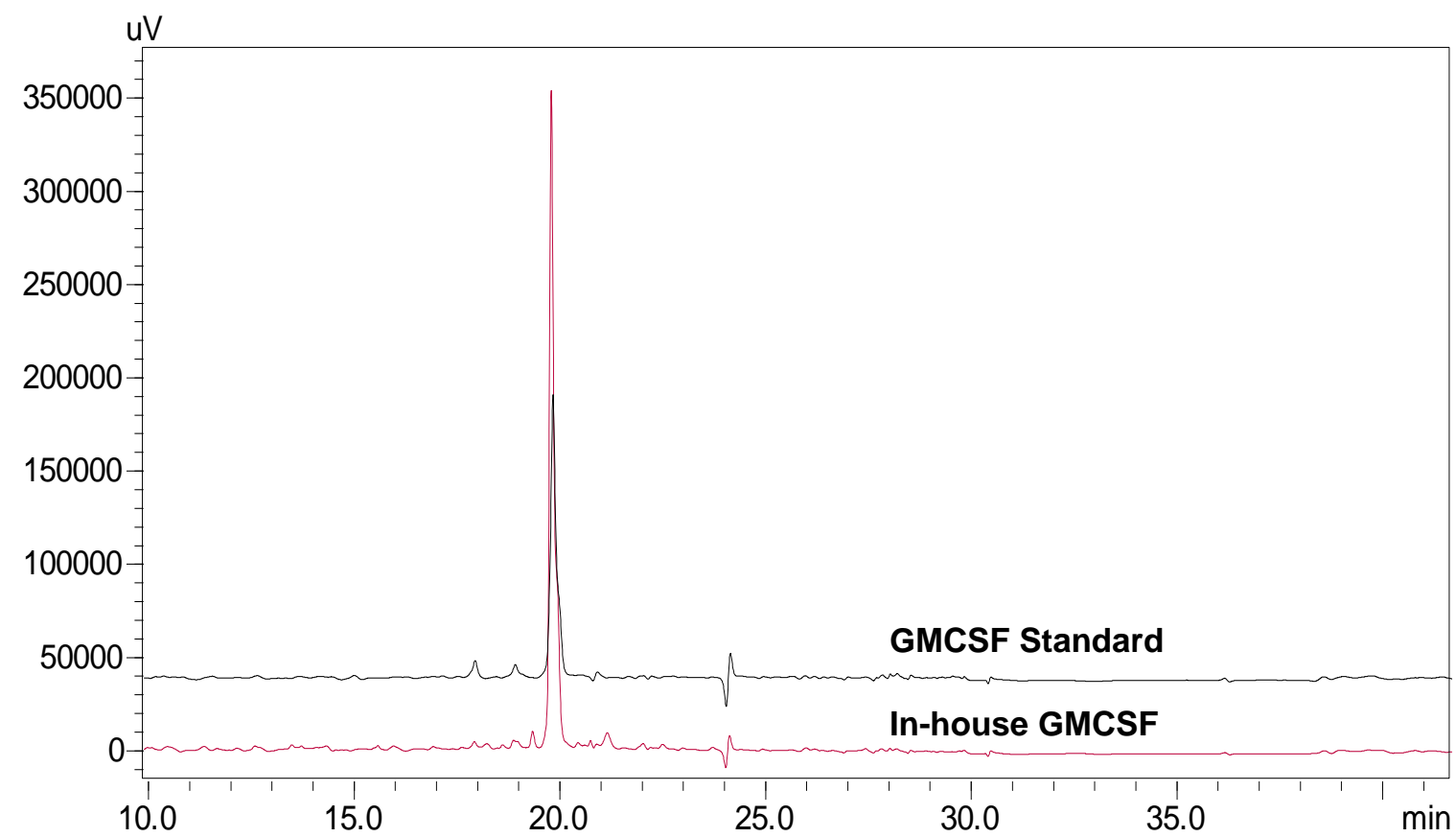

Figure 5. Size Exclusion HPLC profile of standard and in-house purified GMCSF preparations. Size exclusion chromatograph showing comparison of standard GMCSF and in-house purified hGMCSF with optimum mobile phase consisting of $1.15 \mathrm{~g}$ di-sodium hydrogen phosphate, $0.2 \mathrm{~g}$ of potassium hydrogen phosphate and $23.4 \mathrm{~g}$ of sodium chloride. Flow rate was maintained at $0.5 \mathrm{~mL} / \mathrm{min}$ and detection was at $215 \mathrm{~nm}$. Black line represents standard hGMCSF while red line indicates the in-house purified rhGMCSF.

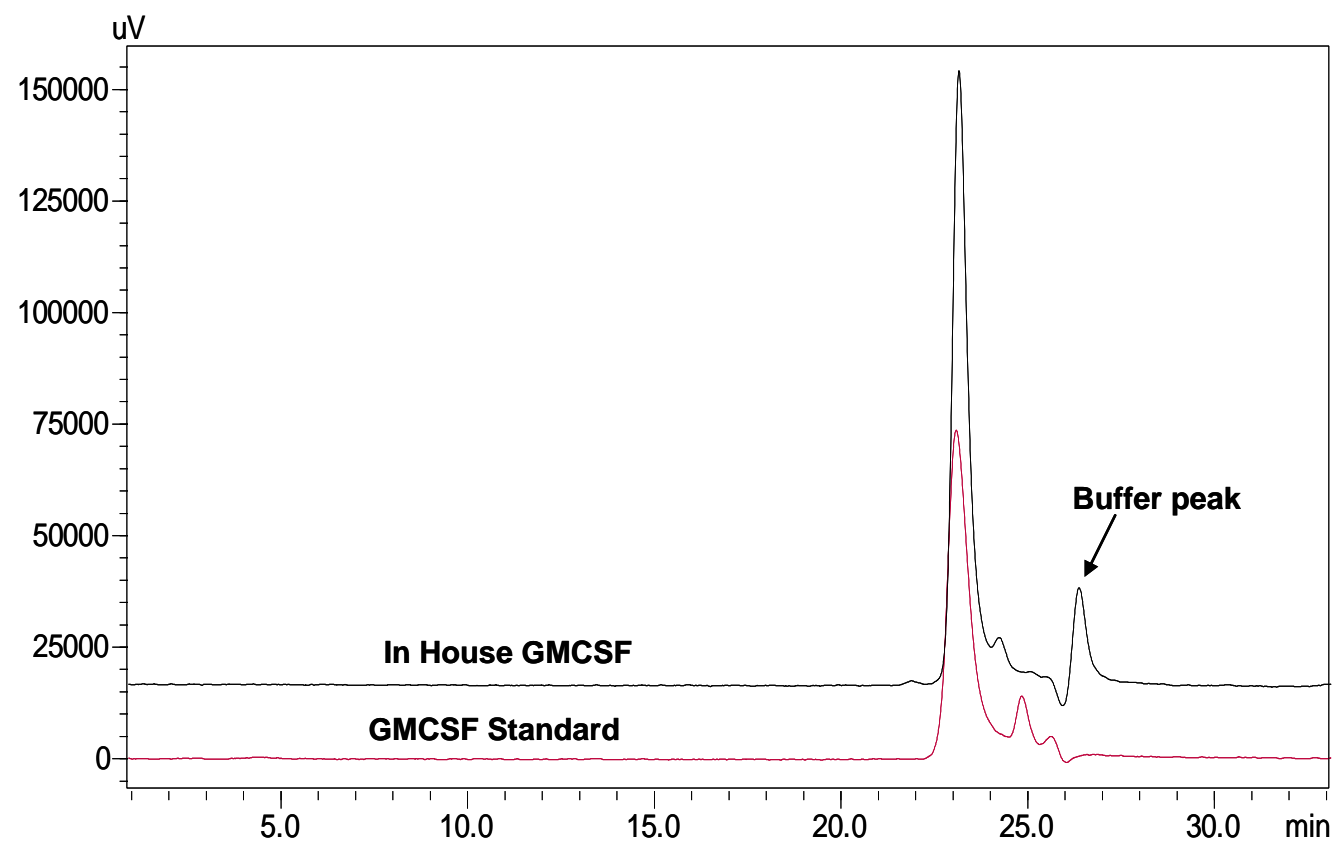


Figure 6. The biological activity of in-house hGMCSF was assessed using TF-1 cell proliferation assay. The activity data was analyzed statistically using Parallel Line Assay software (PLA 2.0). The doses are indicated on the horizontal axis, whereas the corresponding responses are represented on the vertical axis. The individual responses for each treatment are symbolized by the red squares for the standard preparation and by the blue circles for the sample preparation.

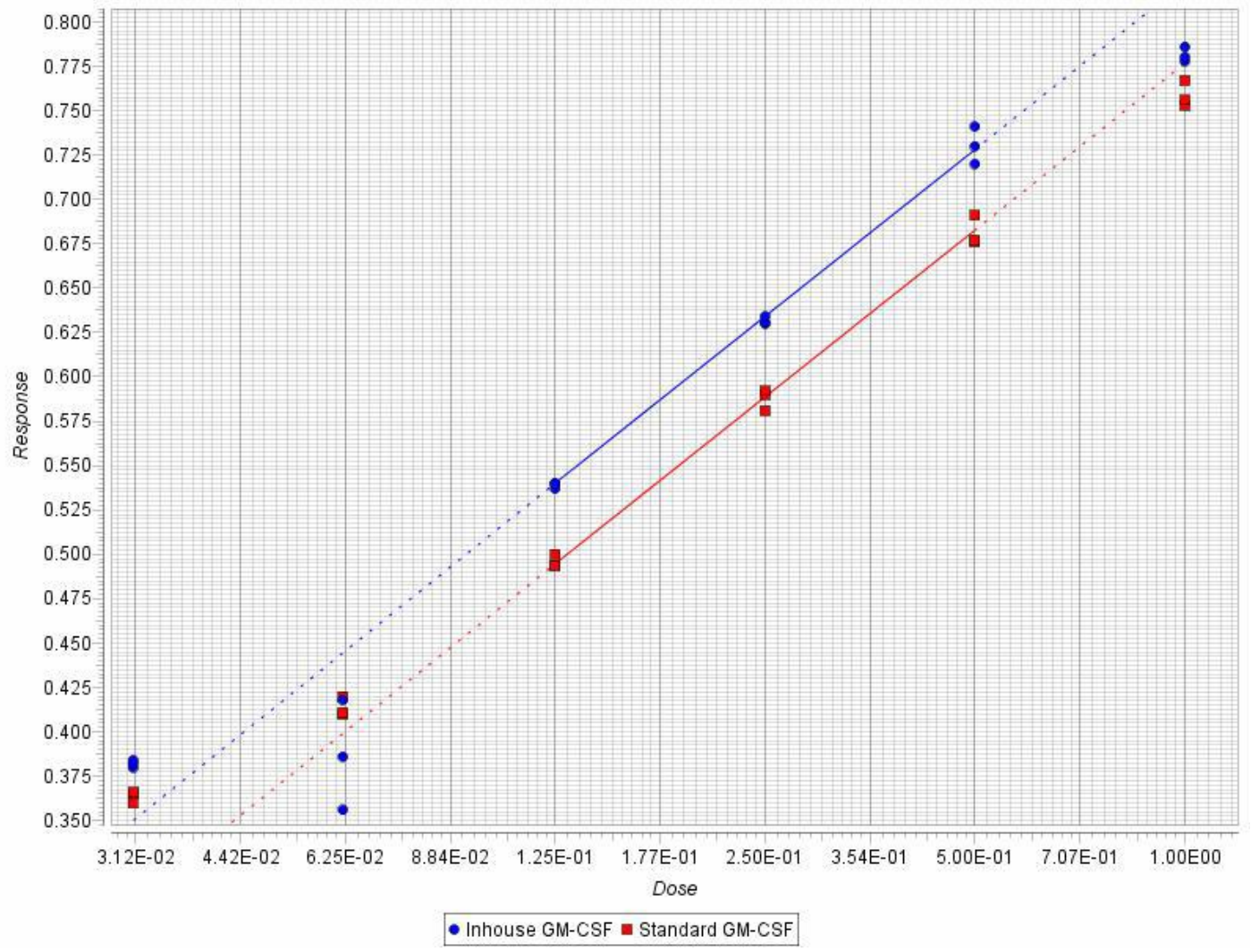

\section{Experimental Section}

\subsection{Cloning of hGMCSF in pET21a Vector and in pET32a as a TRX Fusion Tag}

The hGMCSF gene was amplified using a synthetic gene (GenScript, U.S.) by polymerase chain reaction using the oligos with reduced GC content, forward: 5' CCG CCG GAA TTC GGA TCC GAT GAT GAT GAT AAA GCA (GGC) CCC (ACT) GCC (GTG) CGC (GCC) TCG (TGC) CCC (AGC) AGC (ATC) 3' as and reverse: 5' CCG CCG GAA TTC AAG CTT TCA CTC CTG GAC TGG CTC CCA 3'. The codons within brackets show the original sequence of the human GMCSF gene. PCR cycling conditions were: $94{ }^{\circ} \mathrm{C}$ for 4 min followed by 5 cycles of $94{ }^{\circ} \mathrm{C}$ for $30 \mathrm{~s}, 53{ }^{\circ} \mathrm{C}$ for $30 \mathrm{~s}, 72{ }^{\circ} \mathrm{C}$ for $30 \mathrm{~s}$ and 25 cycles of $94{ }^{\circ} \mathrm{C}$ for $30 \mathrm{~s}, 65{ }^{\circ} \mathrm{C}$ for $30 \mathrm{~s}, 72{ }^{\circ} \mathrm{C}$ for $30 \mathrm{~s}$. The PCR product was cloned into pET21a as an NdeI/HindIII fragment and into pET32a (Novagen, U.S.) as a BamHI/HindIII fragment and all the clones were confirmed by DNA sequencing. 


\subsection{Expression of pET21a-rhGMCSF and pET32a-rhGMCSF in Shake Flask}

The pET21a-rhGMCSF and pET32a-rhGMCSF constructs were separately introduced into BL21 (DE3) codon plus cells and expression was carried out at $37{ }^{\circ} \mathrm{C}$ for $4 \mathrm{~h}$ in $100 \mathrm{~mL}$ Luria Broth containing $100 \mu \mathrm{g} / \mathrm{mL}$ ampicillin. The cells were induced with $1 \mathrm{mM} \mathrm{IPTG}$ and the induced cell pellet was suspended in $10 \mathrm{mM}$ TrisCl, $\mathrm{pH} 8.0$ followed by lysis by sonication (Sonics Vibracell, U.S.). Separation of soluble and insoluble fractions was carried out by centrifugation of the sonicated lysate at 13,000 rpm for $10 \mathrm{~min}$ and both the fractions were analyzed on SDS-PAGE followed by Coomassie blue staining.

\subsection{Bioreactor Studies}

The large scale fermentation was carried out in a $2 \mathrm{~L}$ bioreactor (Sartorius, Germany) with $2 \mathrm{~L}$ in-house media with $1 \%$ glycerol [27]. $2 \%$ of the overnight culture was used as inoculum and the culture was grown at $37{ }^{\circ} \mathrm{C}$ and $\mathrm{pH} 7.0$ up to an $\mathrm{OD}_{600}$ of 18 . The cells were induced with $1 \mathrm{mM}$ IPTG and the culture was grown for another $3 \mathrm{~h}$ until it reached an $\mathrm{OD}_{600}$ of 37 . The culture media was centrifuged at $8000 \times \mathrm{g}$ for $10 \mathrm{~min}$ and the induced cell pellet was resuspended in $10 \mathrm{mM}$ TrisCl $\mathrm{pH}$ 8.0. The suspension was subjected to cell disruption using a high pressure homogenizer (M/S Niro Soavi, Italy) at 800 to 900 bars for two passages. The homogenized cell lysate was centrifuged at $12,500 \times \mathrm{g}$ for $15 \mathrm{~min}$ at $4{ }^{\circ} \mathrm{C}$ to separate the soluble and insoluble fractions.

\subsection{Purification hGMCSF Using $\mathrm{Ni}^{2+}$-NTA Column}

The cleared soluble fraction containing TRX-rhGMCSF was passed through $\mathrm{Ni}^{2+}$-NTA column (GE Healthcare, Sweden) pre-equilibrated with $10 \mathrm{mM}$ TrisCl, pH 8.0 containing $10 \mathrm{mM}$ imidazole (Sigma, U.S.). After washing the column with equilibration buffer, the bound protein was eluted with a gradient of imidazole $(0.1-0.5 \mathrm{M})$. The elute fractions containing the majority of the pure TRX-hGMCSF protein was dialyzed overnight against $10 \mathrm{mM}$ TrisCl, pH 8.0 at $4{ }^{\circ} \mathrm{C}$. For enterokinase reaction, pure TRX-hGMCSF was passed through a second round of purification on $\mathrm{Ni}^{2+}{ }_{-\mathrm{NTA}}$ Sepharose that was pre-equilibrated with TrisCl, $\mathrm{pH} 8.0$ in a batch mode in continuous motion in a rotating mixer. The bound fusion protein, was digested with bovine enterokinase $(4.5 \mathrm{U} / \mathrm{mg}$ of pure fusion protein) (Novagen, U.S.) for four hours at room temperature in the presence of $1 \mathrm{mM} \mathrm{CaCl}_{2}$. The flow through was collected by centrifugation of the contents at $4400 \mathrm{rpm}$ for $10 \mathrm{~min}$ and all samples were analyzed by SDS-PAGE followed by silver staining.

\subsection{Characterization of rhGMCSF by RP-HPLC}

The RP-HPLC was carried out using an ACE C18 $(4.6 \mathrm{~mm} \times 150 \mathrm{~mm})$ column on SHIMADZU LC-2010C $\mathrm{CT}_{\mathrm{HT}}$ HPLC system provided with a quaternary pump, a thermostatted autosampler, a thermostatted column compartment, and a multiple wavelength ultraviolet (UV) detector. Data was collected and analyzed using LC Solution Software (Version 1.24). The mobile phase consisted of $0.1 \%$ TFA in $10 \%$ Acetonitrile (A) and $0.1 \%$ TFA in $90 \%$ Acetonitrile (B). The system was equilibrated with a mixture A-B (90:10) until a stable baseline was obtained. Separations were performed using a stepwise gradient in the following manner: from $10 \%$ to $65 \%$ mobile phase B over a 
period of $20 \mathrm{~min}$, followed by $65 \%$ to $100 \%$ mobile phase B over a period of $3 \mathrm{~min}$. The flow-rate was maintained at $1.0 \mathrm{~mL} / \mathrm{min}$ with detection at $215 \mathrm{~nm}$ at $30{ }^{\circ} \mathrm{C}$.

\subsection{Characterization of rhGMCSF by SE-HPLC}

SEC was performed with SHIMADZU LC-2010C $\mathrm{HT}_{\mathrm{HT}}$ HPLC system provided with a quaternary pump, a thermostatted autosampler, a thermostatted column compartment, and a multiple wavelength ultraviolet (UV) detector. Data was collected and analyzed using LC Solution Software (Version 1.24). A TSK-GEL G3000SWXL $300 \mathrm{~mm} \times 7.8 \mathrm{~mm}$ column (MW range: 1000-500,000 Da) (Tosoh Bioscience LLC, Montgomeryville, PA, U.S.) was chosen for the present studies. . The optimal mobile phase composition consisted of $1.15 \mathrm{~g}$ Di-sodium hydrogen phosphate, $0.2 \mathrm{~g}$ of Potassium hydrogen phosphate and $23.4 \mathrm{~g}$ of sodium chloride. The detector was set at $215 \mathrm{~nm}$ and the flow rate at $0.5 \mathrm{~mL} / \mathrm{min}$.

\subsection{Western Blot Analysis}

Protein samples were separated on denaturing SDS-PAGE and transferred to nitrocellulose membrane. Immunoblot was performed using mouse monoclonal anti-hGMCSF antibody (Santacruz, U.S.) followed by goat anti-mouse secondary antibody (Bangalore Genei, India). The blot was developed using the substrate BCIP/NBT.

\subsection{Bioassay for hGMCSF}

TF-1 cells were maintained in RPMI-1640 with $10 \%$ FBS and $2 \mathrm{ng} / \mathrm{mL}$ rhGMCSF at $37{ }^{\circ} \mathrm{C}$ in $5 \% \mathrm{CO}_{2}$. The cells were starved for $14-16 \mathrm{~h}$ in RPMI-1640 with $2.5 \% \mathrm{FBS}$. After starvation, the cells were plated in RPMI-1640 with 5\% FBS at a seeding density of $1 \times 10^{4}$ cells/well/50 $\mu \mathrm{L}$. Standard and samples were added $(50 \mu \mathrm{L} / w e l l)$ at different concentrations and the plate was incubated for $48 \mathrm{~h}$ at $37{ }^{\circ} \mathrm{C}$ in $5 \% \mathrm{CO}_{2}$. To each well, $20 \mu \mathrm{L}$ of MTS was added and amounts of formazan formed (an indicator of number of live cells, i.e., biological activity) were estimated by measuring $\mathrm{OD}_{490}$ after an additional $4 \mathrm{~h}$ of incubation. The $\mathrm{ED}_{50}$ value was determined and one unit of activity is defined as reciprocal of $\mathrm{ED}_{50}$. The data was analyzed statistically using Parallel Line Assay software (PLA 2.0), which uses three tests for validity of the assay: test of regression, test of linearity and test of parallelism. This analysis gives potency ratio that expresses the potency of the unknown sample in comparison to the potency of the standard. The graph was obtained by plotting responses against doses.

\section{Conclusions}

In this article, we report for the first time the hyper expression of hGMCSF in E. coli at shake flask level with a very high yield ( $44 \mathrm{mg} / \mathrm{L}$ ) which was easily scalable to $\sim 400 \mathrm{mg} / \mathrm{L}$ in a bioreactor. Such a strategy of expressing rhGMCSF demonstrates the possibility of achieving high yield therapeutic proteins and could be applied to other therapeutic proteins. 


\section{Acknowledgements}

The authors wish to thank Kamal Sharma, Managing Director, Lupin Limited, Pune, India for his constant support and encouragement. Thanks are due to Anjali Apte Deshpande for critical reading of the manuscript.

\section{References}

1. Schwanke, R.C.; Renard, G.; Chies, J.M.; Campos, M.M.; Batista, E.L., Jr.; Santos, D.S.; Basso, L.A. Molecular cloning, expression in Escherichia coli and production of bioactive homogeneous recombinant human granulocyte and macrophage colony stimulating factor. Int. J. Biol. Macromol. 2009, 45, 97-102.

2. Armitage, J.O. Emerging applications of recombinant human granulocyte-macrophage colony-stimulating factor. EMBO J. 1985, 4, 2575-2581.

3. DeLamarter, J.F.; Mermod, J.J.; Liang, C.M.; Eliason, J.F.; Thatcher, D.R. Recombinant murine GM-CSF from E. coli has biological activity and is neutralized by a specific antiserum. EMBO J. 1985, 4, 2575-2581.

4. Bhopale, G.M.; Nanda, R.K. Recombinant DNA expression products for human therapeutic use. Curr. Sci. 2005, 89, 614-622.

5. Berrow, N.S.; Bussow, K.; Coutard, B.; Diprosw, J.; Ekberg, M. Recombinant protein expression and solubility screening in E. coli: A comparative study. Acta Crystallogr. 2006, 67, 1218-1226.

6. Sorenson, H.P.; Mortensen, K.K. Advanced genetic strategies for recombinant protein expression in E. coli. Biotechnology 2005, 115, 13-28.

7. Sahdev, S.; Khattar, S.K.; Saini, K.S. Production of active eukaryotic proteins through bacterial expression system: A review of the existing biotechnology strategies. Mol. Cell Biochem. 2008, 307, 249-264.

8. Yin, J.; Li, G.; Ren, X.; Herrler, G.A. Comparative evaluation of the advantages and limitations of frequently used expression systems for foreign genes. J. Biotechnol. 2007, 127, 335-347.

9. Valeria, D.M.; Gunter, S.; Stephanie, B.; Ario, D.M. The solubility and stability of recombinant proteins are increased by their fusion to NusA. Biochem. Biophys. Res. Commun. 2004, 322, 766-771.

10. Cabrita, L.D.; Dai, W.; Bottomley, S.P. A family of E. coli expression vectors for laboratory scale and high throughput soluble protein production. BMC Biotechnol. 2006, 6, 12-19.

11. Srinivasa, B.K.; Muthukumaran, T.; Antony, A.; Samuel, S.D.P.S.; Balamurali, M.; Murugan, V.; Meenakshisundaram, S. Single step intein-mediated purification of hGMCSF expressed in salt-inducible E. coli. Biotechnol. Lett. 2009, 31, 659-664.

12. Lee, A.Y.; Chung, H.K.; Kyong Bae, E.; Hwang, J.S.; Sung, B.W.; Cho, C.W.; Kim, J.K.; Lee, K.; Han, J.Y.; Lee, C.T.; Youn, H.J. A recombinant human G-CSF/GM-CSF fusion protein from E. coli showing colony stimulating activity on human bone marrow cells. Biotechnol. Lett. 2003, 25, 205-211.

13. Smith, H.E. Transcriptional response of E. coli to recombinant protein insolubility. J. Struct. Funct. Genomics 2007, 8, 27-35. 
14. Banerjee, S.; Apte-Deshpande, A.; Mandi, N.; Padmanabhan, S. A novel cytokine derived fusion tag for over-expression of heterologous proteins in E. coli. Int. J Biol. Life Sci. 2009, 1, 139-143.

15. Salunkhe, S.; Prasad, B.; Sabnis-Prasad, K.; Apte-Deshpande, A.; Padmanabhan, S. Expression and purification of SAK-fused human interferon alpha in Escherichia coli. J. Microbial. Biochem. Technol. 2009, 1, 5-10.

16. Harrison, R.G. Expression of soluble heterologous proteins via fusion with NusA protein. Innovations 2000, 11, 4-7.

17. Ackland, C.E.; Berndt, W.G.; Frezza, J.E.; Landgraf, B.E.; Pritchard, K.W.; Ciardelli, T.L. Monitoring of protein conformation by high-performance size-exclusion liquid chromatography and scanning diode array second-derivative UV absorption spectroscopy. J. Chromatogr. A 1991, 540, 187-198.

18. Kaushansky, K.; O’Hara, P.J.; Berkner, K.; Segal, G.M.; Hagen, S.; Adamson, J.W. Genomic cloning, characterization, and multilineage growth-promoting activity of human granulocyte-macrophage colony-stimulating factor. Proc. Natl. Acad. Sci. USA 1986, 83, 3101-3105.

19. Moonen, P. Increased biological activity of deglycosylated recombinant human granulocyte/ macrophage colony-stimulating factor produced by yeast or animal cells. Proc. Natl. Acad. Sci. USA 1987, 84, 4428-4431.

20. Wong, G.G.; Witek, J.S.; Temple, P.A.; Wilkens, K.M.; Leary, A.C.; Luxenberg, D.P.; Jones, S.S.; Brown, E.L.; Kay, R.M.; Orr, E.C. Human GM-CSF: Molecular cloning of the complementary DNA and purification of the natural and recombinant proteins. Science 1985, 228, 810-815.

21. Miyajima, A.; Otsn, K.; Schreurs, J.; Bond, M.W.; Abrams, J.S.; Arai, K. Expression of murine and human granulocyte-macrophage colony-stimulating factors in S. cerevisiae: Mutagenesis of the potential glycosylation sites. EMBO J. 1986, 5, 1193-1197.

22. Burgess, A.W.; Begley, C.G.; Johnson, G.R.; Lopez, A.F.; Williamson, D.J.; Mermod, J.J.; Simpson, R.J.; Schmitz, A.; de Lamarter, J.F. Purification and properties of bacterially synthesized human granulocyte-macrophage colony stimulating factor. Blood 1987, 69, 43-51.

23. Belew, M.; Zhou, Y.; Wang, S.; Nystrom, L.E.; Janson, J.C. Purification of recombinant human granulocyte-macrophage colony-stimulating factor from the inclusion bodies produced by transformed Escherichia coli cells. J. Chromatogr. 1994, 679, 67-83.

24. Srinivasa, B.K.; Antony, A.; Muthukumaran, T.; Meenakshisundaram, S. Construction of intein-mediated hGMCSF expression vector and its purification in Pichia pastoris. Protein Expr. Purif. 2008, 57, 201-205.

25. Cowgill, C.; Ozturk, A.G.; John, R. Protein Refolding and Scale Up; Shukla, A.A., Etzel, M.R., Gadam, S., Eds.; Taylor \& Francis: New York, NY, USA, 2007; pp. 124-158.

26. Sletta, H.; Tondervik, A.; Hakvag, S.; Aune, T.E.V.; Nedal, A.; Aune, R.; Evensen, G.; Valla, S.; Ellingsen, T.E.; Brautaset, T. The presence of $N$-terminal Secretion signal sequences leads to strong stimulation of the total expression levels of three tested medically important proteins during high-cell-density cultivations of Escherichia coli. Appl. Environ. Microbiol. 2007, 73, 906-912. 
27. Mandi, N.; Soorapaneni, S.; Rewanwar, S.; Kotwal, P.; Prasad, B.J.; Mandal, G.; Padmanabhan, S. High-yielding recombinant staphylokinase in bacterial expression system-cloning, expression, purification and activity studies. Protein Expr. Purif. 2009, 64, 69-75.

(C) 2011 by the authors; licensee MDPI, Basel, Switzerland. This article is an open access article distributed under the terms and conditions of the Creative Commons Attribution license (http://creativecommons.org/licenses/by/3.0/). 